аспирант, ФГБОУ ВО «Ангарский государственный технический университет», e-mail: evdockimencko.dima@yandex.ru

Чечет Борис Федорович,

к.ф.н., доиент кафедры общественных наук ФГБОУ ВО «Ангарский государственный технический университет», e-mail:bchechet_54@mail.ru

КОМПОЗИЦИОННЫЕ МАТЕРИАЛЫ, КОТОРЫЕ МЕНЯЮТ НАШУ ЖИЗНЬ

\title{
COMPOSITE MATERIALS THAT CHANGE OUR LIFE
}

\footnotetext{
Аннотация. В статье проанализированы композиционые материалы в сравнении с другими материалами, их применение в промышленности и в обычной жизни.

Ключевые слова: композит, аналог, материал, экологическая культура.

Abstract. The article analyzes composite materials and comparison with other materials, application in industry and in everyday life.

Keywords: composite, analog, material, environmental memtality.
}

Научно-технический и технологический прогресс не стоит на месте, практически каждый день ученые решают новые задачи, в том числе, улучшающие качество жизни человека, будь то строительство жилья или космического спутника. Для решения этих проблем требуются новые материалы, отвечающие современным требованиям.

Композиционные материалы (композит) являются одним из видов новых материалов. Но что такое композит? Композит это многокомпонентный материал, изготовленный из двух или более материалов, отличающихся своими исходными свойствами, а в результате производится материал с совершенно новыми, иногда уникальными, свойствами.

Композиты позволяют иметь заданное сочетание разнородных свойств: высокой удельной прочности и жесткости, жаропрочности, износостойкости, теплозащитных свойств и др. Спектр свойств композитов невозможно получить при использовании обычных материалов.

Например, обычная фанера состоит из нескольких слоев шпона, склеенного клеем на основе формальдегидной смолы. Но этот простой композит сделал настоящий технический прорыв в таких отраслях как строительство, изготовление мебели, подшипников и др. Для рядового потребителя не заметно, как используется фанера и другие композиты в обычной жизни и он не оценивает их роль и побочные эффекты их использования в жизнедеятельности человека.
A такие композиционные материалы как стеклопластики, углепластики, текстолиты дали толчок развитию электроники, космонавтики, авиационной, автомобильной промышленности и др. Они позволили уменьшить вес, увеличить прочность, облегчить человеческие трудозатраты на изготовление деталей по сравнению с аналогичными традиционными материалами, такими как металлы и их сплавы.

Но важны не только лучшие технические показатели и технологические преимущества композиционных материалов. Вместе с этими плюсами уменьшилась себестоимость композиционных изделий. Например, полипропиленовая труба, армированная стекловолокном, в среднем стоит дешевле в 6 раз по сравнению со стальной (в примере указана труба торгового представителя VALTEC и номинальными размерами ду 20) [1]. На этом примере видна разница в цене, но не менее важно и то, что срок службы полипропиленовой трубы гораздо дольше, чем у стальной.

И так во всех сферах жизни человека, композитные материалы уверенно заняли востребованную нишу в плане общедоступности и эффективности. Обширное их применение стало ключевым фактором развития этих материалов. Эти материалы позволяют развиваться самым разнообразным сферам производства и жизнедеятельности человека, не используя дефицитные или дорогостоящие аналоги. Этот путь по сущности совпадает с эпохами развития человека от медного 
века к бронзовому, от бронзового века к железному и так далее, когда открытие новых материалов и технологий определяло очередной скачок в развитии общества. Но XX век был настоящим локомотивом развития материаловедения, что способствовали две мировых войны и гонка вооружений (холодная война) между СССР и США. Для соперничества в вооружении требовались всё новые материалы, их требовалось разрабатывать, создавать соответствующие технологии, находить пути рационального использования новых материалов. Например, технологическая «гонка» в авиации привела к созданию карбона, кевларов, различных арамидных тканей и многого другого. Одним из конкретных примеров применения композитных материалов в военной сфере стал самолет SR-71 фирмы LOCKHEED, разработанный в 70-е годы XX столетия. Этот самолёт был изготовлен из титанового сплава с широким использованием полимернокомпозитных материалов, что дало этому самолету технологическое преимущество, в том числе, максимальную скорость 3529 км/ч, которая долгое время была мировым рекордом [2].

Композитные материалы в широком спектре применяются в медицине, например, в стоматологии применяются стеклоиономерные цементы для пломбирования и реставрации зубов. Искусственные кости из биорезорбируемого композита уже стали применяться в современной медицине, для их изготовления может применяться 3D принтер, что позволяет изготовить фрагмент по индивидуальному образцу. Таким образом, композитные материалы и технологии позволили существенно улучшить качество медицинских услуг и здоровья населения.

Еще одним положительным качеством композиционных материалов является их вторичная переработка. Существенная часть композитных материалов после своего рабочего цикла может быть отправлена на станции переработки, где их сортируют, превращают в крошку и используют вторично в промышленных производствах.

Конечно, возможности переработки зависят от научного, технического и технологического, а в итоге от экономического развития государства. Но существенное значение имеет и характер культурных норм, в том числе, связанных с экологией, утвердившихся в той или иной стране. Существует взаимосвязь между уровнем переработки искусственных, в том числе композиционных, материалов и перечисленными факторами. Например, Швеция, развитая индустриальная страна, с развитой, в силу географических, исторических и ментальных особенностей, экологической культурой, перерабатывает более 99\% мусора, производимого внутри государства. Но более того, Швеция закупает мусор в соседних странах, перерабатывает его и получает определённую экономическую выгоду [3].

Противоположным примером является Китай, который в ближайшем прошлом был типичным аграрным государством, а в последние десятилетия встал на путь индустриализации, и занимает первое место по уровню промышленного производства. При этом в Китае практически не перерабатывается мусор, и долгое время эта страна импортировала отходы из других стран, предоставляя свои территории для мусорных полигонов. Естественно, ни о каком вторичном использовании композитных материалов в этом случае речи идти не может. И только в 2021 г. вели запрет на ввоз мусора [4]. К чему приводит такая политика? К тому что, страна может быть «похоронена под грудами мусора». Загрязнение водных источников, эрозия почв, разрушение крупных экосистем, это только начало на пути экологической катастрофы мирового масштаба.

В нашей жизни появляются все новые машины, технологии, которые меняют нашу жизнь, от фанеры до углепластиков, от фанерного биплана до композитного сверхзвукового самолета. Наша жизнь меняется вместе с развитием материаловедения. Появление новых материалов помогает людям облегчить труд, улучшая его качество и удешевляя конечный продукт. Но при этом должна развиваться культура использования композитных материалов, утилизации или, в идеальном варианте, переработки вторсырья, в том числе, композитных материалов.

А эта задача напрямую связана с экологической культурой. $\mathrm{B}$ экологической культуре можно выделить три уровня: экологическая культура государственных структур, принимающих и реализующих соответствующие решения (от муниципального уровня до уровня общегосударственного), экологическая культура общества в целом, которая, на третьем уровне, проявляется в бытовом поведении, имеющем отношение к 
экологии, каждого отдельного индивида.

На государственном уровне важны решения, направленные на инвестиции и стимулирование разработок, производства, использования и утилизации или вторичной переработки композиционных материалов, разработка соответствующего законодательства, и контроль за его исполнением.

Отношение общества к изделиям из композитных материалов в значительной степени определяется спецификой общества. Выделим условно три типа общества: традиционное (консервативное) общество (не знает рациональную сферу применения композитных материалов и риски с ним связанные), общество потребления (не хочет знать, оно потребляет).

Третий тип общества обозначим как «разумное общество», как некий, потенциально возможный, идеальный конструкт.

Традиционные общества также вовлекаются в потребление изделий из композитных материалов. Ведь производители композитных материалов - это преимущественно крупные корпорации, которые стремятся к максимальному расширению рынков сбыта своей продукции, в том числе и традиционных обществах. Но это, как правило, бедные общества, с низким уровнем образования, технологической и экологической культуры. Скорее всего, в таких обществах отсутствуют технологии, производства и специалисты необходимые для вторичной переработки изделий из композитных материалов. В результате отслужившие свой срок изделия из композитов, или просто морально устаревшие, занимают своё место на многочисленных мусорных свалках, которые превращаются уже в серьёзную глобальную проблему.

Важны изменения ценностных акцентов и формирование экологического мента- литета и, как культурах традиционного типа, так и в культуре общества потребления. Следует отметить, что ростки экологического менталитета (волонтёрское движение, связанное, в частности, с очисткой от мусора природных территорий, формируются, прежде всего, именно в наиболее развитых странах. В частности, это связано с более высоким уровнем образования в таких странах [6. C. 622].

Д. Даймонд приводит впечатляющие примеры, как крупные компании, такие, как «Шеврон», осознавая, какие финансовые, материальные, но и имиджевые потери, могут нести экологические катастрофы, сознательно идут на дополнительные траты, чтобы таких катастроф не допустить [6. С. 621]. Использование композиционных материалов в решении подобных проблем может быть очень эффективным.

Но производство и эксплуатация изделий из композиционных материалов могут быть связаны с новыми экологическими и медицинскими рисками. Вряд ли та же фанера, содержащая в своём составе формальдегидные смолы, в условиях жаркого и влажного климата не выделяет вредные для здоровья человека вещества. Важно развитие потребительской культуры, формирование экологического менталитета, превращение экологической и технологической ответственности в устойчивую тенденцию, важно научиться подавлять экологически вредные традиции и потребительское отношение к природе в стремлении к комфорту. Но не менее важным является инвестиции в разработку технологий и производств новых менее вредных композитов, внедрение и обеспечение неизбежной ответственности за их безответственную эксплуатацию и утилизацию.

\section{СПИСОК ЛИТЕРАТУРЫ}

1. Композит [Электронный ресурс]. URL: // ru.wikipedia.org/wiki/ Композитный материал (Дата обращения: 1.10.2021 г.)

2. Композиционные материалы [Электронный ресурс]. - URL:// proiz-teh.ru/ kom pozicionnye-materialy.html (Дата обращения: 4.10.2021г.)

3. История изобретения полипропилена [Электронный ресурс]. - URL:https://unitreidgroup.com/poleznoe/istorija-izobretenija-poli propilena (Дата обращения: 11.10.2021 г.)
4. Полипропилен [Электронный ресурс]. - URL://ru.wikipedia.org/wiki/Полипропилен (Дата обращения: 15.10.2021 г.)

5. Свойства композиционных материалов [Электронный ресурс] - URL:// studme. org/116808/tehnika/kompozitsionnye_materialy (Дата обращения: 21.10.2021 г.)

6. Даймонд Дж. Коллапс: Как и почему одни общества приходят к процветанию, а другие - к гибели / Дж. Даймонд; пер. с англ. - М.: Астрель: CORPUS, 2012. 